\title{
Effects of Occupational Noise on the Hearing Ability of Outpatient Clinic Nurses in Different Classes of Hospitals in Guangzhou
}

\author{
Donglan Liư ${ }^{1}$ Xun Zeng1, Li Wang2* \\ ${ }^{1}$ Outpatient Clinic of Internal Medicine Department, The First Affiliated Hospital, Sun Yat-sen University, Guangzhou, China \\ ${ }^{2}$ Department of Healthcare, The First Affiliated Hospital, Sun Yat-sen University, Guangzhou, China \\ Email: *wanglimer@163.com
}

How to cite this paper: Liu, D.L., Zeng, X. and Wang, L. (2020) Effects of Occupational Noise on the Hearing Ability of Outpatient Clinic Nurses in Different Classes of Hospitals in Guangzhou. International Journal of Clinical Medicine, 11, 154-162.

https://doi.org/10.4236/ijcm.2020.114016

Received: February 28, 2020

Accepted: April 4, 2020

Published: April 7, 2020

Copyright $\odot 2020$ by author(s) and Scientific Research Publishing Inc. This work is licensed under the Creative Commons Attribution International License (CC BY 4.0).

http://creativecommons.org/licenses/by/4.0/

\begin{abstract}
Background: Occupational noise can induce hearing impairment. Work-related hearing impairment has become a growing threat to medical practitioners who feel anxious about occupational noise exposure and its health outcomes or even experience auditory dysesthesia (including drumming, distending pain in the ears, and otalgia) after long-term exposure to a noisy work environment. Objective: To investigate the effects of occupational noise on the hearing ability of outpatient clinic nurses in Grade III, Level A and Grade II, Level A hospitals in Guangzhou. Methods: During June 2019, noise monitoring was performed by quantifying the noise levels at four measuring points (reception, waiting area, hallway, blood-sampling room) in five Grade III, Level A and five Grade II, Level A hospitals, in Guangzhou, four times a day (8 AM, 10 AM, 2 PM, and 4 PM) for 19 working days, using a professional noise measuring application for smartphones. The measurements were verified and used to create a database in Excel. Data analysis was conducted using SPSS22.0, and questionnaires were distributed to nurses who had been working at outpatient clinics for five years and above to assess the impacts of occupational noise exposure on the hearing ability. Results: In the Grade III, Level A hospitals, the sound levels at the four measuring points during the specific time periods were $4.92-6.75 \mathrm{~dB}$ above the permissible limit of $55 \mathrm{~dB}$ and were all significantly higher than the sound levels at the outpatient clinics of the Grade II, Level A hospitals $(\mathrm{P}<0.001)$. Outpatient clinic nurses who had been serving with the Grade III, Level A hospitals for at least five years ( $\mathrm{n}$ $=140$, mean age: $44 \pm 5.1$ ) had a prevalence ratio of auditory dysesthesia higher than their counterparts $(n=110$, mean age: $42 \pm 6.1)$ in the Grade II, Level A hospitals $(\mathrm{P}<0.01)$. Conclusions: Exposure to excess noise can lead
\end{abstract}


to auditory dysesthesia in outpatient clinic nurses. Compared to those from Grade II, Level A hospitals, outpatient clinic nurses from Grade III, Level A hospitals are at higher risk of auditory dysesthesia. The noise levels at outpatient clinics should be closely monitored, and effective measures should be taken to reduce occupational noise exposure. Outpatient clinic nurses should enhance protective measures and receive preventive health exams on a regular basis.

\section{Keywords}

Noise, Outpatient Clinic Nurse, Auditory Dysesthesia, Survey

\section{Introduction}

Hazardous occupational noise is a public health threat. Occupational noise brings gradual damage to the hearing system and is particularly linked to hearing impairment. Existing studies on noise-induced hearing impairment largely focus on workers in the manufacturing industry, with only very few reports covering the impacts of occupational noise exposure on medical practitioners. As the medical and health sector develops, occupational safety and health are considered an increasingly important research interest.

In the recent five years, anxiety grows in hospitals as nurses have experienced auditory dysesthesia (including drumming, distending pain in the ears, and otalgia) closely associated with day-to-day exposure to occupational noise even though relevant symptoms are usually relieved after they leave their workplaces. Studies have suggested that there is a clear link between occupational noise-induced hearing loss and noise intensity, age, and length of service [1] [2]. In China, researchers mainly focus on occupational noise exposure in enterprises. For instance, Chen et al. [3] [4] [5] pointed out that workers in such economic subsectors as automobile manufacturing, site operation, and textile industries were high-risk populations for noise-induced hearing impairment and cardiovascular problems; of the workers having been exposed to occupational noise for five years, $36.04 \%$ were diagnosed with hearing impairment; those who had been employed for over five years were more likely to have hearing problems, blood pressure conditions, and abnormal ECG patterns. A foreign study suggested [6] that both patients and medical practitioners could be severely affected by noise pollution in hospitals. Chinese researchers largely emphasize the physiological and psychological impacts on patients exposed to a noisy hospital environment. Wang et al. [7] [8] [9] [10] showed that a noisy environment had a strong impact on a patient's emotions and could raise the risk of anxiety by up to 91.07\%. Despite all that, noise-induced auditory dysesthesia in medical practitioners is rarely reported. To fill the gap, we carried out a one-month investigation concerning occupational noise and distributed questionnaires to nurses who had been working at the same outpatient clinics for at least five years for 
self-evaluation of auditory dysesthesia (including drumming, distending pain in the ears, and otalgia). The results are reported as follows:

\section{Subjects and Methods}

\subsection{Subjects}

Five Grade III, Level A and five Grade II, Level A hospitals were selected randomly for noise monitoring at their outpatient clinics. Questionnaires were distributed to 250 nurses who had been working at these outpatient clinics for at least five years, including 140 from the Grade III, Level A hospitals (range: 35 56; mean age: $44 \pm 5.1$ ) and 110 from the Grade II, Level A hospitals (range: 28 54; mean age: $42 \pm 6.4)$.

\subsubsection{Hospitals}

Five Grade III, Level A hospitals with at least 2000 outpatient visits per day and five Grade II, Level A hospitals with 400 to 700 outpatient visits per day were chosen for noise monitoring when the ambient temperature was $22^{\circ} \mathrm{C}-26^{\circ} \mathrm{C}$ and the relative humidity was $50 \%-70 \%$.

\subsubsection{Inclusion Criteria}

Nurses were eligible for inclusion if they 1 ) had been working at the same outpatient clinics for at least five years, and 2) denied having a familial history of hearing loss, known ototoxic drug usage, excessive use of earphone, preexisting otological problems, known exposure to organic solvents, viral infection/vascular disease-induced inner hair cell dysfunction or physiological and structural damage to the inner ear, and any other underlying conditions. This study has obtained informed consent from all participants.

\subsection{Methods}

\subsubsection{Noise Monitoring}

Noise monitoring was performed using a professional sound level meter application (iDOBOOKER, Beijing, China) at four measuring points (reception, waiting area, hallway, blood-sampling room) in each of the 10 hospitals, four times a day (8 AM, 10 AM, 2 PM, and 4 PM) for 19 working days. Smartphones were installed with the noise measuring application and placed about $1.5 \mathrm{~m}$ away from windows, $1.2-1.5 \mathrm{~m}$ above the ground, and at least $1 \mathrm{~m}$ away from other reflecting surfaces. Parallel measurement (three times in total) was made at every measuring point during each period $(1 \mathrm{~min})$. For each measuring point, there were 12 measured values as the sound level during each period was measured three times. On this basis, a total of 3040 measured values were obtained after 19 working days, and the sound level at every measuring point was averaged over the specific period.

\subsubsection{Questionnaire Survey}

Questionnaires were randomly distributed to 140 outpatient clinic nurses from 
the Grade III, Level A hospitals and 110 from the Grade II, Level A hospitals. The sample size of this survey was determined using formula $n=Z^{2} \sigma^{2} / d^{2}$. We used the confidence interval of $95 \%$, the significant level of 0.05 , the power of 0.8 , and the overall standard deviation of 0.5 , which were substituted into the formula to reach the minimum sample size as 97 . The questionnaire is designed independently and has passed the assessment of reliability and validity of expert judgment. The questionnaire asks details about age, sex, length of service, whether the respondent has a familial history of hearing loss, known ototoxic drug usage, excessive use of earphone, preexisting otological problems, known exposure to organic solvents, viral infection/vascular disease-induced inner hair cell dysfunction or physiological and structural damage to the inner ear, and any other underlying conditions, whether the respondent experiences auditory dysesthesia (including drumming, distending pain in the ears, and otalgia) and if so, whether such symptoms are relieved after the respondent leaves the workplace. (This questionnaire survey focuses on the self-evaluation of auditory dysesthesia. Hearing exam will be performed in the follow-up study).

\subsection{Indicators}

\subsubsection{Noise}

GB 3096-2008 Environmental Quality Standard for Noise and GB 22337-2008 Emission Standard for Community Noise. China Environmental Science Press (Beijing) [11].

\subsubsection{Nurses' Subjective Experience}

Whether they experienced auditory dysesthesia (including drumming, distending pain in the ears, and otalgia) and if so, whether such symptoms were relieved after they left their workplaces.

\section{Statistical Analysis}

All statistics were registered, and a database was created and verified via Excel. SPSS22.0 was used for data analysis. Measurement data were expressed in the form of "mean \pm standard deviation $(\mathrm{x} \pm \mathrm{s}$ )"; enumeration data were presented by percentage $(\mathrm{n} \%)$. The $t$-test and the chi-squared test were applied in the data analysis, with $\mathrm{P}<0.05$ being considered statistically significant.

\section{Results}

As shown in Table 1, there is no statistically significant difference between the outpatient clinic nurses from Grade III, Level A and Grade II, Level A hospitals in age, length of service, and length of outpatient service, which indicates a high degree of comparability.

Table 2 suggests that at all measuring points, the outpatient clinics of the Grade III, Level A hospitals have higher sound levels compared to the outpatient clinics of the Grade II, Level A hospitals, and the differences are statistically significant. In other words, the outpatient clinics of the Grade III, Level A hospitals 
Table 1. Demographic characteristics of nurses from the Grade III, Level A and Grade II, Level A hospitals.

\begin{tabular}{ccccc}
\hline $\begin{array}{c}\text { Demographic } \\
\text { Characteristics }\end{array}$ & $\begin{array}{c}\text { Grade III, Level A } \\
(\mathrm{n}=140 / 100 \%)\end{array}$ & $\begin{array}{c}\text { Grade II, Level A } \\
(\mathrm{n}=110 / 100 \%)\end{array}$ & $t$-value & $p$-value \\
\hline Age & $43.76 \pm 5.11$ & $42.38 \pm 6.16$ & 1.936 & 0.054 \\
$\begin{array}{c}\text { Length of service } \\
\text { Length of } \\
\text { outpatient service }\end{array}$ & $23.63 \pm 6.07$ & $22.73 \pm 7.15$ & 1.076 & 0.283 \\
\hline
\end{tabular}

Table 2. Sound levels ( $\mathrm{dB}$ ) at the measuring points in the Grade III, Level A and Grade II, Level A hospitals.

\begin{tabular}{ccccc}
\hline Area & $\begin{array}{c}\text { Grade III, Level } \\
\text { A Hospital }\end{array}$ & $\begin{array}{c}\text { Grade II, Level } \\
\text { A Hospital }\end{array}$ & $t$-value & $p$-value \\
\hline Reception & $60.78 \pm 4.87$ & $53.36 \pm 3.46$ & 13.520 & $<0.001$ \\
Waiting area & $61.75 \pm 4.98$ & $53.76 \pm 3.30$ & 14.507 & $<0.001$ \\
Hallway & $59.92 \pm 6.64$ & $52.98 \pm 3.49$ & 9.934 & $<0.001$ \\
Blood-sampling room & $59.37 \pm 5.19$ & $52.48 \pm 2.39$ & 12.482 & $<0.001$ \\
\hline
\end{tabular}

are faced with a greater noise challenge than those of the Grade II, Level A hospitals.

Table 3 reveals that compared to the Grade II, Level A hospitals, the Grade III, Level A hospitals have a higher proportion of outpatient clinic nurses who experience auditory dysesthesia (including drumming, distending pain in the ears, and otalgia), and the difference shows statistical significance. Further, about $66.43 \%$ of the outpatient clinic nurses from the Grade III, Level A hospitals report relief of relevant symptoms after work, which indicates that occupational noise is closely associated with the occurrence of auditory dysesthesia in these nurses.

\section{Discussion}

\subsection{Definition of Noise and Relevant Standards}

Noise [12] is defined as a sound produced by industrial production, construction, transportation or social life that causes disturbance to the surrounding living environment. Environmental noise pollution means the phenomenon where the noise level exceeds a specific threshold and causes disturbance to people's everyday life, work and study.

Threshold Noise Level in Urban Environment (dB).

\begin{tabular}{ccc}
\hline Category & Daytime & Night-time \\
\hline 0 & 50 & 40 \\
1 & 55 & 45 \\
2 & 60 & 50 \\
3 & 65 & 55 \\
4 & 70 & 55 \\
\hline
\end{tabular}


Table 3. Manifestations of auditory dysesthesia in outpatient clinic nurses from the Grade III, Level A and Grade II, Level A hospitals.

\begin{tabular}{cccccc}
\hline Manifestations & $\begin{array}{c}\text { Grade III, Level A } \\
(\mathrm{n}=140 / 100 \%)\end{array}$ & $\begin{array}{c}\text { Grade II, } \\
\text { Level A } \\
(\mathrm{n}=110 / 100 \%)\end{array}$ & $\chi^{2}$ & $p$-value \\
\hline Drumming & $36 / 25.71 \%$ & $0 / 0.00 \%$ & 33.04 & $<0.01$ \\
Distending pain in the ears & $36 / 25.71 \%$ & $0 / 0.00 \%$ & 33.04 & $<0.01$ \\
Otalgia & $30 / 21.43 \%$ & $0 / 0.00 \%$ & 26.79 & $<0.01$ \\
$\begin{array}{c}\text { Relief of symptoms (if any) } \\
\text { after work }\end{array}$ & $93 / 66.43 \%$ & - & - & - \\
\hline
\end{tabular}

Outpatient clinics and other medical spaces are subject to Category 1 , that is, the sound level should remain below $55 \mathrm{~dB}$ during the daytime and $45 \mathrm{~dB}$ in the evening. According to the applicable national standards, noise in daytime means the sound level in such areas beyond the permissible limit of $55 \mathrm{~dB}$ [13].

\subsection{The Influence of Different Levels of Occupational Noise on Clinic Nurses}

The two groups of outpatient clinic nurses from the Grade III, Level A and Grade II, Level A hospitals are highly comparable in the light of the fact that they have no significant difference in age, length of service, and length of outpatient service. After noise monitoring for 19 working days, it was found that the average daytime sound levels at the four measuring points of the five Grade III, Level A hospitals were as follows: waiting area $61.75 \pm 4.98 \mathrm{~dB}>$ reception $60.78 \pm$ $4.87 \mathrm{~dB}>$ hallway $59.92 \pm 6.64 \mathrm{~dB}>$ blood-sampling room $59.37 \pm 5.19 \mathrm{~dB}$; the average daytime sound levels at the four measuring points of the five Grade II, Level A hospitals were as follows: waiting area $53.76 \pm 3.30 \mathrm{~dB}>$ reception $53.36 \pm 3.46 \mathrm{~dB}>$ hallway $52.98 \pm 3.49 \mathrm{~dB}>$ blood-sampling room $52.48 \pm 2.39$ $\mathrm{dB}$. Clearly, the average sound levels at the four measuring points of the five Grade III, Level A hospitals during the 19 working days were all above the daytime limit of $55 \mathrm{~dB}$, whereas none of the five Grade II, Level A hospitals exceeded the given threshold. The outpatient clinics of the Grade III, Level A hospitals are noisier than those of the Grade II, Level A hospitals probably because they have a greater number of daily outpatient visits, inadequate outpatient settings, and larger patient flows. Studies have shown that the proportion of outpatient clinic nurses from Grade III, Level A hospitals who suffer from auditory dysesthesia is $72.86 \%$ higher than that of Grade II, Level A hospitals, which provides support for concluding that long-term occupational noise exposure predisposes nurses to auditory dysesthesia.

\subsection{Reports on Noise Health Effect(s)}

A survey regarding noise and urban dwellers' health suggests that the incidence of hypertension increases by $3 \%$ when the noise level in an area is up by $1 \mathrm{~dB}$. This is in agreement with the findings of Pang et al. [14] [15] [16] [17], which 
revealed that long-term exposure to high-level noise could lead to hearing impairment and nonspecific injury of the cardiovascular system. Ryherd et al. [18] [19] pointed out that working in a noisy environment for a long time might cause dizziness, memory loss, irritability, fatigue, and low work efficiency; also, it could affect interpersonal communication and lower the energy level. When this occurs in medical practitioners, they may make mistakes in diagnosis and treatment. Sometimes loud noises can cause discomfort. Studies [20] [21] showed that most nurses did not fully understand noise health outcomes and their knowledge of noise largely varied because of sex, age, and length of service; if not keenly aware of the importance of self-protection against occupational noise at the beginning, they might face serious consequences. In this study, the incidence rates of drumming, distending pain in the ears, and otalgia in the outpatient clinic nurses from the Grade III, Level A hospitals were 25.71\%, 25.71\%, and $21.43 \%$, respectively, while $66.43 \%$ reported relief of relevant symptoms after leaving the workplaces, which is significantly higher than the proportion of symptom relief in the Grade II, Level A hospitals and implies that for outpatient clinic nurses in Grade III, Level A hospitals, occupational noise is probably an important risk factor of auditory dysesthesia. A heightened awareness of self-protection and early prevention and control play a critical role in preventing occupational noise-induced hearing loss [22]. Therefore, hospitals should implement effective noise control to protect patients and medical practitioners.

\section{Conclusions}

Exposure to excess noise can lead to auditory dysesthesia in outpatient clinic nurses. Compared to those from Grade II, Level A hospitals, outpatient clinic nurses from Grade III, Level A hospitals are at higher risk of auditory dysesthesia. The noise levels at outpatient clinics should be closely monitored, and effective measures should be taken to reduce occupational noise exposure. Outpatient clinic nurses should enhance protective measures and receive preventive health exams on a regular basis.

This study has its limitations as other risk factors of auditory dysesthesia that may affect the study results have not been fully discussed.

Further study is needed for comparative analysis of auditory dysesthesia in nurses when multiple measures are taken to reduce noise exposure in the outpatient clinics of Grade III, Level A hospitals.

\section{Conflicts of Interest}

The authors declare no conflicts of interest regarding the publication of this paper.

\section{References}

[1] Lu, X.-T., Zhang, J.-X., Xu, S.-H., et al. (2018) Noise-Induced Hearing Loss and Influencing Factors of Workers in Different Sectors of a Lager Tire Manufacturing Plant in Heifei City. Occupation and Health, 34, 2476-2480. 
[2] Lie, A., Skogstad, M., Johnsen, T.S., et al. (2014) A Cross-Sectional Study of Hearing Thresholds among 4627 Norwegian Train and Track Maintenance Workers. BMJ Open, 4, e005529. https://doi.org/10.1136/bmjopen-2014-005529

[3] Chen, Y.-L., Wang, X., Liu, X.-X., Han, F., Kang, N. and Hu, W.-J. (2019) Effects of Occupational Noise Exposure on Asymmetric Hearing Loss in Automobile Manufacturing Workers. Chinese Journal of Industrial Hygiene and Occupational Diseases, 37, 260-264.

[4] Pang, Z.-J. and Lu, A.-Z. (2019) Analysis of the Influence of Enterprise Productive Noise on the Hearing and Cardiovascular System of Workers. Shanghai Medical \& Pharmaceutical Journal, 40, 57-59.

[5] Wang, S.-T. (2019) Effect of Occupational Noise Exposure in a Textile Plant on Hearing and Cardiovascular System. China Health Industry, 9, 154-155.

[6] Juang, D.F., Lee, C.H., et al. (2010) Noise Pollution and Its Effects on Medical Care Workers and Patients in Hospitals. International Journal of Environmental Science \& Technology, 7, 705-716. https://doi.org/10.1007/BF03326180

[7] Wang, J.-F., Tian, P., Pan, L.-X., et al. (2012) Psychological Impact of Noise on Patients Undergoing Surgery and Intervention. Journal of Qiqihar Medical College, 33, 2401-2402.

[8] Zhang, B.-L., Hao, Y.-Y., He, B.-Y. and Zhao, Y. (2013) Physiological and Psychological Impacts of Noise in Operating Room on Patients Undergoing Surgery. Chinese Journal of Modern Nursing, 19, 2546.

[9] Liu, Y.-X. (2012) Effect of Noise in Operating Room on Physiological Indexes of Patients Undergoing Surgery. Chinese Community Doctors, 14, 188.

[10] Wang, M.-Q. (2013) Investigation of Anxiety Status of Patients with Sudden Deafness. Chinese Journal of Modern Nursing, 19, 2148-2150.

[11] Ministry of Environmental Protection, General Administration of Quality Supervision, Inspection and Quarantine (2008) GB 3096-2008 Environmental Quality Standard for Noise and GB 22337-2008 Emission Standard for Community Noise. China Environmental Science Press, Beijing.

[12] (2018) Order No.77 of the President of the People's Republic of China. Law of the People's Republic of China on Environmental Noise Prevention and Control.

[13] Wang, X.-M. and Liu, Y.-L. (2006) Application of Voice Assessment. Baotou Medicine, No. 1, 29-30.

[14] Pang, L.-J. and Zhang, S.-Y. (2015) Physical Examination Analysis of Individuals Subject to Occupational Noise Exposure in Kunshan City. For All Health, 31, 12-13.

[15] Chen, Z.-R. (2007) Analysis of Noise Influence in Hearing and Cardiovascular System of Industrial Worker. Practical Preventive Medicine, 14, 766-767.

[16] Mai, W.-H., Peng, H., Lin, D.-J., et al. (2012) Influence of Occupational Noise on Workers' Cardiovascular Systems. Occupational Health and Emergency Rescue, 30, 305-307.

[17] Liu, X.-M., Li, J., Li, Q., et al. (2012) Effect of Occupational Noise on ECG Patterns of Forge Shop Workers. Chinese Medicine Modern Distance Education of China, $10,132$.

[18] Ryherd, E.E., Waye, K.P. and Ljungkvist, L. (2008) Characterizing Noise and Perceived Work Environment in a Neurological Intensive Care Unit. Journal of the Acoustical Society of America, 123, 747-756. https://doi.org/10.1121/1.2822661

[19] Deng, X.-C. (2018) Situation and Protection Measures of Noise Pollution in Surgery ICU. Nursing Practice and Research, 15, 20-21. 
[20] Wu, N.-H. and Wu, J.-Q. (2013) Noise Pollution in Intensive Care Units and Preventive Measures. Journal of Qilu Nursing, 19, 54-56.

[21] Wu, C.-W., Huang, Y.-X. and Zhou, P.-F. (2015) Adverse Effect of Noise on Patients in Intensive Care Units and Preventive Measures. Contemporary Nurses (Periodical), No. 2, 187-188.

[22] Zhu, H.-T., Guan, L.-N. and Jiang, H.-Q. (2016) Pathological Mechanisms of Noise-Induced Hearing Loss: A Review of Recent Research. Chinese Journal of Otology, 14, 681-685.

\section{Supplemental}

Table S1. Results of expert judgment $(\mathrm{n}=12)$.

\begin{tabular}{cccccc}
\hline Questionnaire & $\begin{array}{c}\text { Completely } \\
\text { feasible } \\
(\# / \%)\end{array}$ & $\begin{array}{c}\text { Strongly } \\
\text { feasible } \\
(\# / \%)\end{array}$ & $\begin{array}{c}\text { Feasible } \\
(\# / \%)\end{array}$ & $\begin{array}{c}\text { Weakly } \\
\text { feasible } \\
(\# / \%)\end{array}$ & $\begin{array}{c}\text { Infeasible } \\
(\# / \%)\end{array}$ \\
\hline Content validity & $4 / 33.33$ & $5 / 41.67$ & $3 / 25.00$ & & \\
Construct validity & $4 / 33.33$ & $6 / 50.00$ & $2 / 16.67$ & & \\
\hline
\end{tabular}

Table S2. Results of test-retest reliability (two weeks after the preceding questionnaire survey, $\mathrm{n}=50)$.

\begin{tabular}{cccc}
\hline & $\mathrm{N}$ & $\mathrm{R}$ & $\mathrm{P}$ \\
\hline Questionnaire & 50 & 0.88 & $\mathrm{P}<0.01$ \\
\hline
\end{tabular}

